\title{
Auroral Sporadic-E Ionization
}

Robert D. Hunsucker and Leif Owren

\author{
Contribution from Geophysical Institute, University of Alaska, College, Alaska
}

(Received October 30, 1961; revised February 26, 1962)

Auroral type sporadic- $E$ recorded with the C-3 ionosonde at College, Alaska during the IGY winter 1957-58 has been compared with simultaneous all-sky camera observations and other data for times of auroral activity. Both frame-by-frame comparisons of ionograms and all-sky camera photographs and studies of statistical relations between $f E_{\mathrm{s}}$, the auroral activity index, and the local magnetic $K$-index were made.

The sequential study shows that $f E$ s increases with auroral activity and reaches a maximum value of 5 to $10 \mathrm{Mc} / \mathrm{s}$ when the aurora is overhead. The statistical study indicates good correlation between the zenithal auroral activity index and $f E \mathrm{~s}$, with a correlation coefficient of 0.544 .

\section{Introduction}

The present state of knowledge concerning the sporadic $E(E \mathrm{~s})$ phenomena has been surveyed by Thomas and Smith [1959]. These authors considered all recognized types of sporadic $E$ occurring in the three latitude zones designated respectively as equatorial, temperate, and auroral. Their summary shows clearly in which respects present information is incomplete and, in particular, that a gap exists with regard to auroral sporadic $E$ ionization. The purpose of this paper is to supplement the available information on the sporadic $E$ occurring in the auroral zone. More specifically, it deals with the characteristics of sporadic $E$ observed with a standard ionosonde at the auroral zone station College, Alaska during auroral activity and with related subjects.

The nomenclature and definitions adopted for ionospheric vertical soundings during the International Geophysical Year [Beynon and Brown, 1957] will be used in this communication. The following concepts are of particular importance for the sequel:

Esa (auroral): This type is mostly seen at high latitudes, usually during the night hours, and has been associated with magnetic and auroral activity. It has a rather well-defined flat or gradually rising lower edge, with stratification and diffuse (spread) echo present above it. This sometimes extends several hundred kilometers in virtual height.

$f E \mathrm{~s}$ (or $\left.f_{\mathrm{o}} E \mathrm{~s}\right)$ : The ordinary wave top frequency corresponding to the highest frequency at which a mainly continuous trace is observed. It should be noted that at least four of the sporadic $E$ types recognized in the IGY classification system occur in the auroral zone; namely, the Es-auroral type already defined together with the $E_{\text {s }}$ forms designated as flat (f), retardation (r), and slant (s). A recent investigation by Bates [1961], based on simultaneous sweepfrequency backscatter soundings and VHF observations of radar aurora, indicates that the occurrence of the slant $E_{\mathrm{s}}\left(E_{\mathrm{ss}}\right)$ form is at least partly associated with magnetic and auroral activity at College. Therefore the type designation Es-auroral is some- what ambiguous and should be understood to characterize a form peculiar to the auroral zone. Esa should not be thought to be the only form of sporadic $E$ which can be associated with auroral activity, but preferably considered as the form typically observed with a vertical incidence ionosonde during auroral activity overhead the station. A perusal of the attributes for the types Esa and $E_{\text {ss }}$ listed by Thomas and Smith (loc. cit.) shows that these are largely the same. Both forms are stated to be a nighttime phenomenon at College, Alaska of the nonblanketing type with spread echoes and as being correlated with magnetic activity.

The approach in this paper is to study the radio reflecting properties of the $E$ layer, notable as indicated by the value of $f E s$ and its variation, at times when the occurrence and degree of visual auroral activity is known from simultaneous observations without regard to classification details. Therefore we are concerned with the auroral sporadic E ionization in the wider, physical sense rather than the restricted type which is designated by the too inclusive term Es-auroral. The data used in this investigation were mainly obtained during the IGY winter $1957-58$ at College, Alaska (geomagnetic coordinates $64^{\circ} .65 \mathrm{~N}, 256^{\circ} .56 \mathrm{E}$ ). These data resulted from vertical incidence soundings of the ionosphere with a NBS Model C-3 ionosonde operated by the Geophysical Institute for the National Bureau of Standards, and simultaneous photographs of the visual aurora with an IGY allsky camera [Elvey and Stoffregen, 1957]. Some use has also been made of the data obtained during the same period by the Magnetic Observatory of the U.S. Coast and Geodetic Survey at College, Alaska.

In section 2 we compare ifrst, by means of plots, the hourly scaled values of $f E$ s during a selected shorter period with an auroral index derived from simultaneous all-sky camera observations. Next, the correlation between $f E$ s and the auroral index is deduced from all avaliable data. Finally, a frameby-frame comparison of simultaneous ionograms and all-sky camera photographs is made. 


\section{Visual Aurora and the Auroral E Top Frequency}

\subsection{Detailed Comparison of $\mathrm{fEs}$ and Auroral Index}

The hourly routine scalings of the sporadic $E$ top frequency $\left(f E_{\mathrm{s}}\right)$ from the ionograms secured at College, Alaska were compared with an auroral index derived from all-sky camera observations at the same location [Tryon, 1959]. This index is recorded at 15 min intervals centered on the hour and quarter hours. The value is based on three photographs taken 1 min apart and centered on the 15-min interval. The value corresponding to the frame showing the greatest activity is usually recorded. Therefore simultaneous pairs of values for $f E s$ and the auroral index were avaliable for comparison and have been used throughout this part of the investigation. The value of the auroral index is determined according to the following descriptions :

0 . No aurora visible:

1. Aurora just visible. May be very distant or very faint.

2. Moderate activity limited to a small part of the sky.

3. Moderate activity over most of the sky, or small amount of intense activity.

4. Moderate activity over entire sky, or intense activity over most of the sky.

5. Intense activity over entire sky, or very intense activity over most of the sky.

6. Very intense activity over the entire sky.

In general, the moderate activity consists of homogeneous arcs and other quiet forms. The intense activity is brighter, and of more active forms, than the moderate. The very intense activity is so bright as to conceal the detail of the forms. Suffixes indicate whether the activity was in the north, zenith, or south respectively, but such suffixes are used only when the activity covers a limited part of the sky and the distinction is obvious.

The plots in figure 1 show the relation between the sporadic- $E$ top frequency and the visual auroral index for the period 3-14 December 1958. The number enclosed in the circle appearing in the upper right-hand corner of each plot is the sum of the three-hourly $K$-index values for College, Alaska over the given time interval. The data symbols used in the plots have the following meaning:

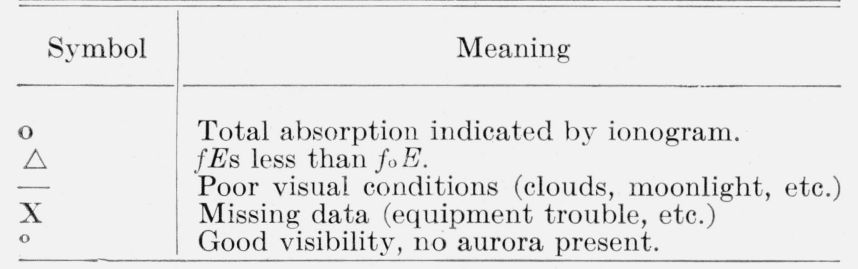

The periods $6-7$ and $9-10$ December are missing because of equipment malfunctions.

The main result of the detailed, hour-by-hour comparison of the $f E \mathrm{~s}\left(f_{0} E \mathrm{~s}\right)$ and auroral index values is, as indicated by the plots of figure 1 , that periods of high $f E \mathrm{~s}$ correspond to period of high au roral activity. A quantitative statement of this qual- itative result will be given in the following subsection. It is well to note that the auroral index does not give a completely reliable indication of the location or type of visual aurora. It will be shown below that high values of $f E$ s are closely correlated with the occurrence of aurora at the zenith, and that accordingly the relationship between $f E$ s and auroral activity is stronger than indicated by figure 1.

\subsection{Statistical Comparison of $f E_{\mathrm{s}}$ and Zenithal Auroral Index}

Simultaneous data from the ionosonde and all-sky camera at College, Alaska are available for the periods December 1957 through March 1958 and October through December 1958. Rather rigorous quality requirements were imposed on the observations for inclusion in this study. Thus, only auroral indices obtained from all-sky camera observations under good conditions were admitted, while all doubtful ionosonde data were rejected. Moreover, the auroral indices were further restricted to those associated with activity in the zenith or over the entire sky. This procedure limited the number of usable pairs of $f E_{\mathrm{s}}$ and auroral index values to merely 62. Although on the low side, the number of simultaneous pairs of values is still large enough to permit statistically significant deductions. The value pairs are plotted in the scatter diagram shown as figure 2, which indicates a strong correlation between the value of $f E s$ and the zenithal auroral index. This impression is confirmed by the computed cross-correlation coefficient of $r=0.544$.

Cross-correlation coefficients have also been computed between the values of the three-hourly $K$ indices for College, Alaska and respectively the auroral index and the $f E$ s value with the following results:

$K$-index versus auroral index $\quad r=0.490$

$K$-index versus $f E \mathrm{~s} \quad r=0.012$.

The degree of correlation obtained between the $K$-index and the auroral index is consistent with the results found by other investigators for College, Alaska ['T. N. Davis, private communication]. The apparent lack of significant correlation between magnetic activity as indicated by the $K$-index and $f E$ s is probably due to the fact that the $K$-index represents an a verage over a $3-\mathrm{hr}$ period while the auroral sporadic $E$ is a rapidly changing phenomenon, leading to rapid variations in the value of $f E \mathrm{~s}$. It would be more meaningful to use the local magnetic Q-index for the correlation computations, but unfortunately this index has not been scaled for the College, Alaska magnetograms during IGY.

\subsection{Relationship Between $f E_{\mathrm{S}}$ and Zenith Aurora}

In an early study of the relationship between visual aurora and vertical ionosonde observations, Heppner, Byrne, and Belon [1952] found a high correlation between certain zenithal auroral forms and the value of $f E s$. In particular, rayed bands at the zenith gave the highest correlation with $f E$ s, while complete absorption was indicated 100 percent of the time when pulsating auroral forms were overhead. In the 1952 investigation the auroral data consisted of visual ob- 

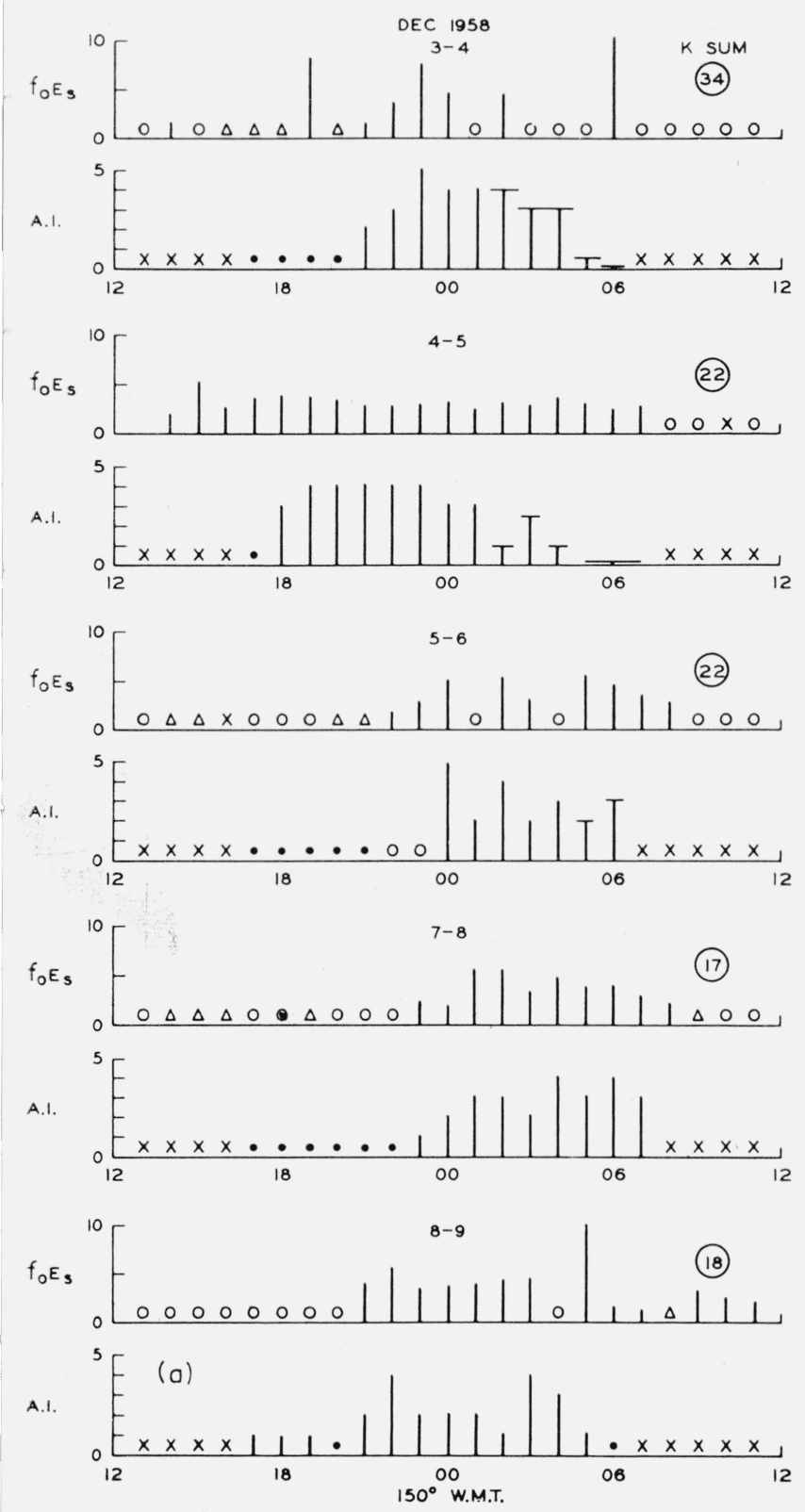

Figure 1a. Relation of all-sky camera auroral index (A.I.) to sporadic-E cutoff frequency (fEs).

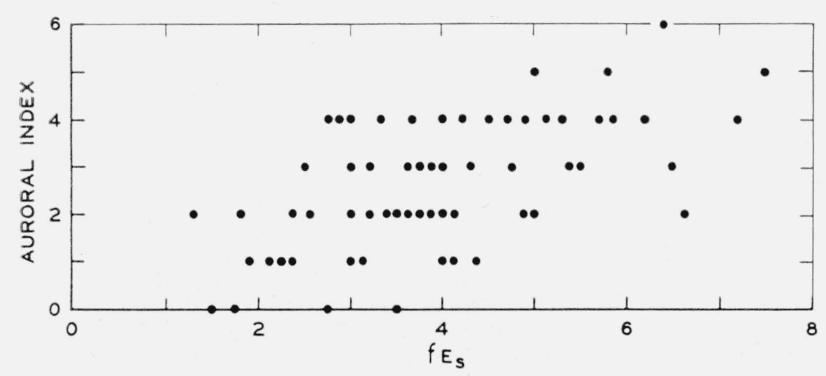

FIgure 2. Scatter diagram of auroral index and sporadic-E cutoff frequency (fEs).
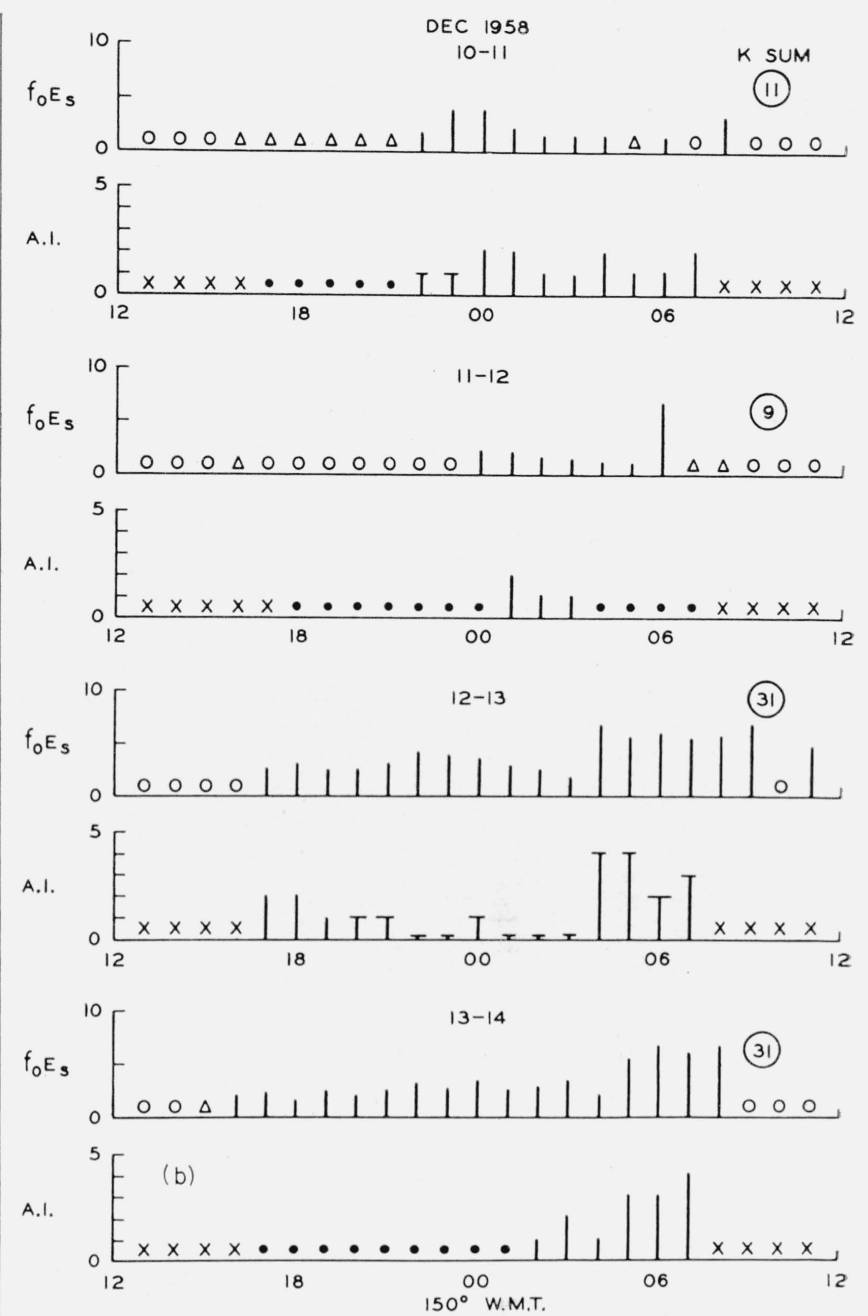

Figure 1b. Relation of all-sky camera auroral index (A.I.) to sporadic-E cutoff frequency (fEs).

servations and the ionospheric data came from two different ionosondes (a CIW-DTM Model 3 and a NBS Model C-3). Similar results were obtained at Pt. Barrow, Alaska by Knecht [1956] using a C-2 ionosonde and visual auroral observations for 10 clear nights.

These earlier results may now be extended and made more precise by taking advantage of the fact that all-sky camera photographs of the visual aurora can be matched with ionograms made with a single (C-3) ionosonde. The atlas of simultaneous all-sky camera and ionosonde records reproduced in figures 3 to 10 shows clearly the close relationship which exists between the visual aurora and the condition of the spordaic $E$ layer. The records were obtained during the period 3-9 December 1958. They are arranged in chronological order with the all-sky camera photographs oriented such that geomagnetic north is upwards.

Since some of the details of the auroral forms displayed in the all-sky camera photos may be lost in the photo reproduction process, a precise description of the atlas sequences has been prepared using the original all-sky camera photos and $\mathrm{C}-3$ ionograms. 
This description is presented in tabular form, and will help to clarify the relation between the auroral and ionospheric phenomena. The nomenclature for classification of sporadic- $E$ traces given by Thomas and Smith [1959] is employed. The standard I.U.G.G. classification of auroral types given in Ratcliffe [1960] is followed in the description of the visual aurora.

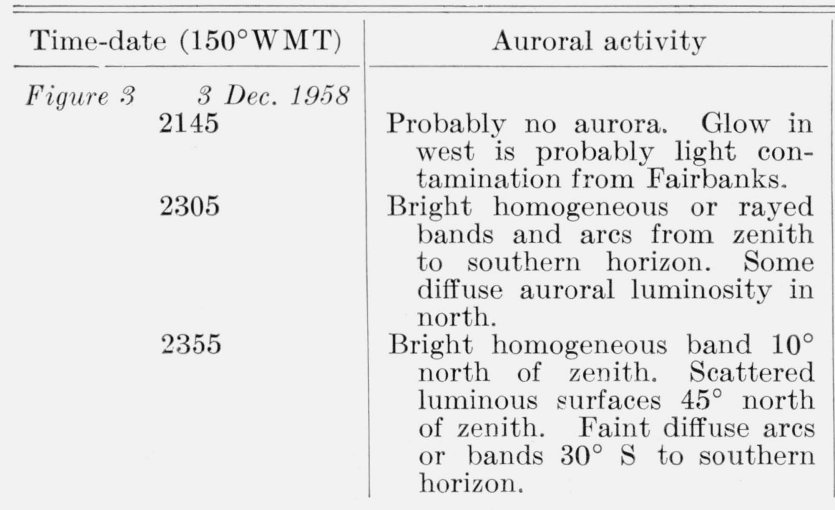

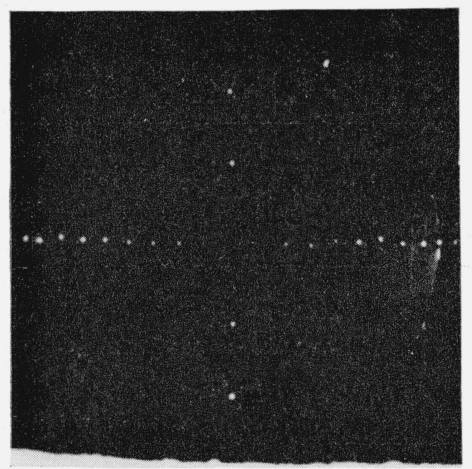

\section{DEC 3,1958}
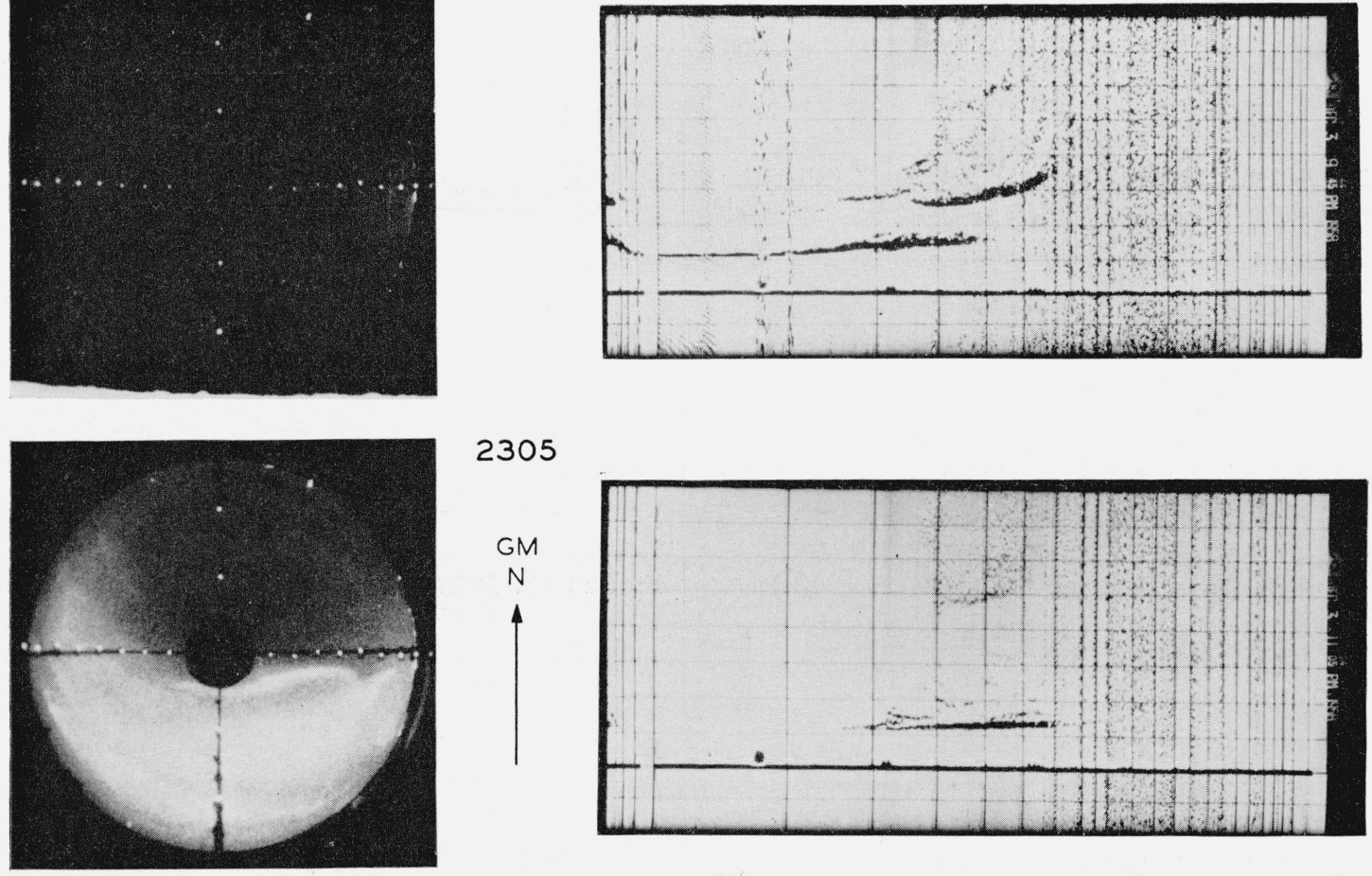

\section{5}
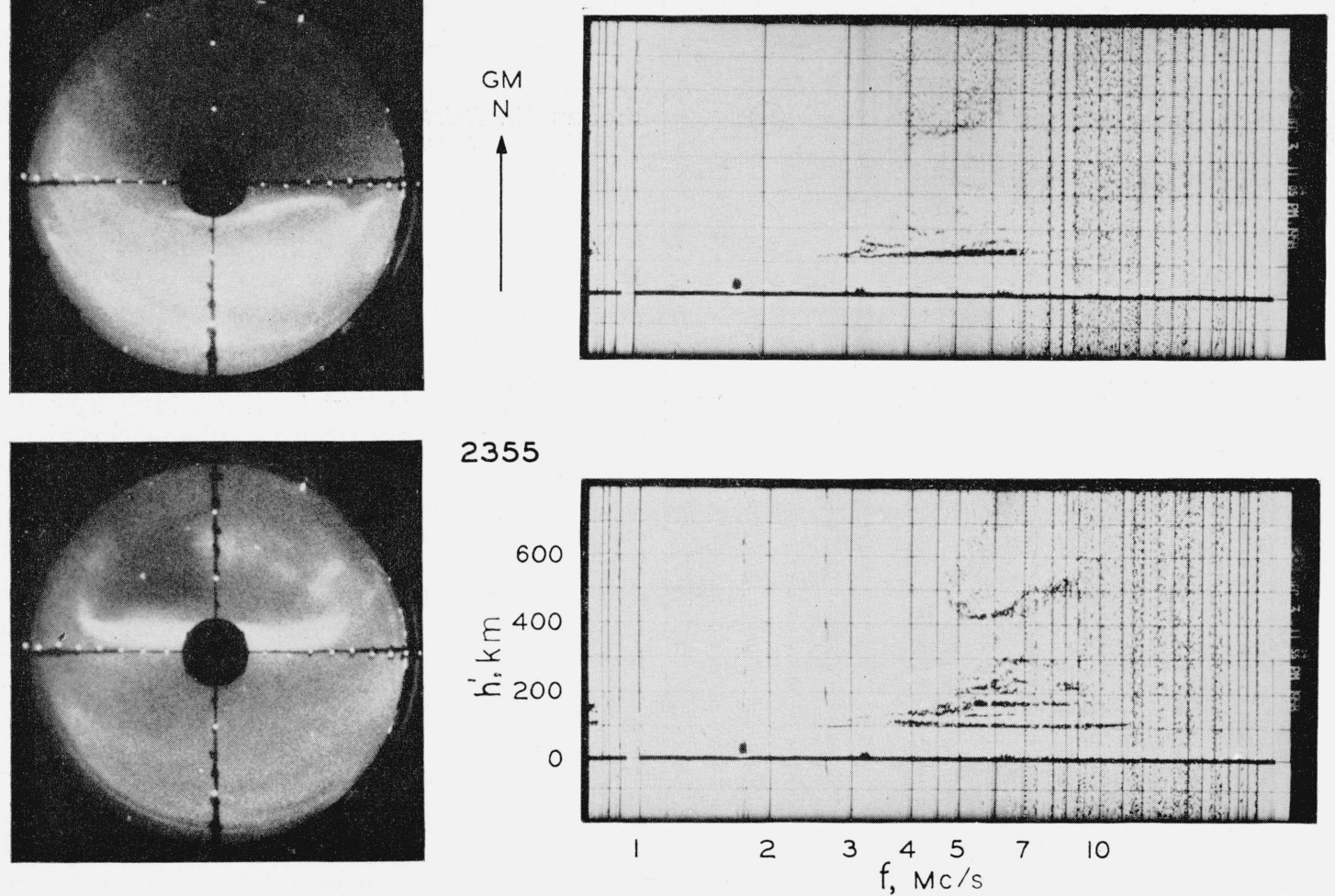

Figure 3. Simultaneous $C-3$ vertical ionosonde and all-sky camera record. 
Time-date $\left(150^{\circ} \mathrm{WMT}\right)$

Figure $4 \quad 4$ Dec. 1958 1830

1930

2105

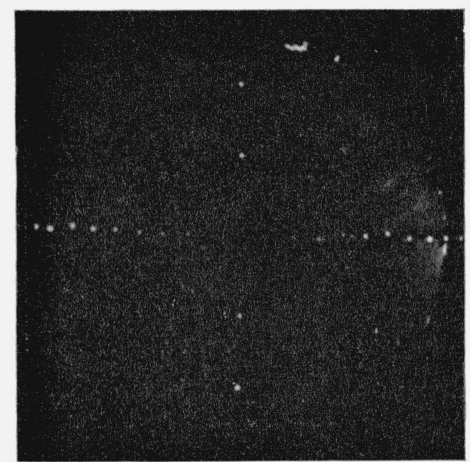

1830

DEC 4, 1958

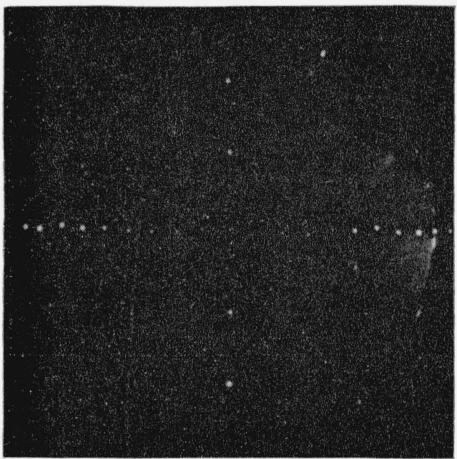

1930

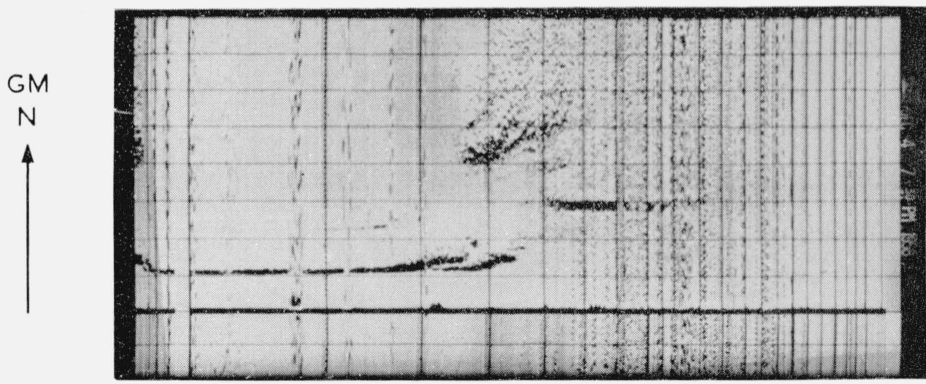

2105

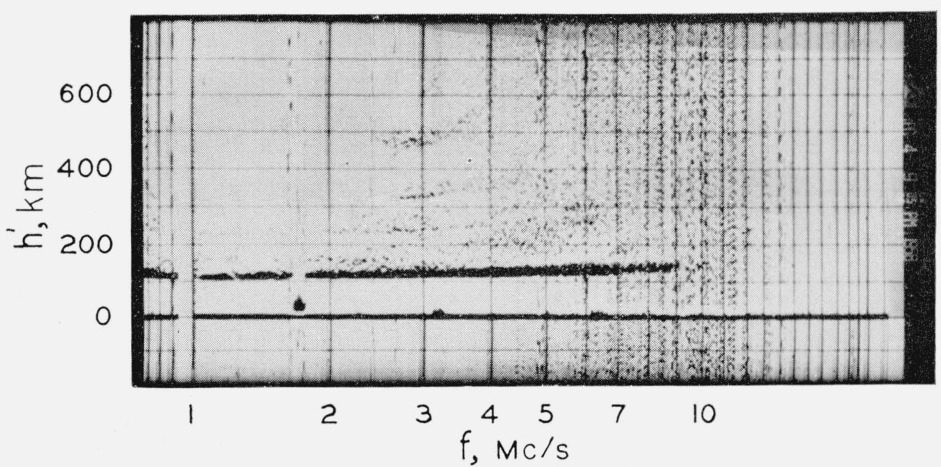

Figure 4. Simultaneous $C-3$ vertical ionosonde and all-sky camera record. 


\begin{tabular}{|c|c|}
\hline Time-date $\left(150^{\circ} \mathrm{WMT}\right)$ & Auroral activity \\
\hline Figure $5 \underset{2255}{4}$ Dec. 1958 & $\begin{array}{l}\text { Medium-to-bright rayed bands } \\
\text { from magnetic zenith to } 75^{\circ} \\
\text { north, brightest in northwest. } \\
\text { Faint-to-medium diffuse ho- } \\
\text { mogeneous arc at } 75^{\circ} \text { south. } \\
\text { Bright rayed arc at } 70^{\circ} \text { north. } \\
\text { Faint diffuse homogeneous arc } \\
\text { at } 80^{\circ} \text { south. }\end{array}$ \\
\hline
\end{tabular}

Ionospheric events

$f E \mathrm{~s} \approx 7 \quad \mathrm{Mc} / \mathrm{s} \quad$ (Esa. Considerable spread- $F$. Considerable stratification in E-region,

$f E_{\mathrm{s}} \approx 3 \mathrm{Mc} / \mathrm{s}(E \mathrm{sr})$. Reduced spread- $F$ increased stratification in $F$-region.
Remarks

This sequence is included to show the complex nature of the ionosonde record during typical aurorally-disturbed conditions. The value of $f E \mathrm{~s}$ is higher when auroral activity occurs near the zenith (2255) than for activity at lower elevation angles (2305).

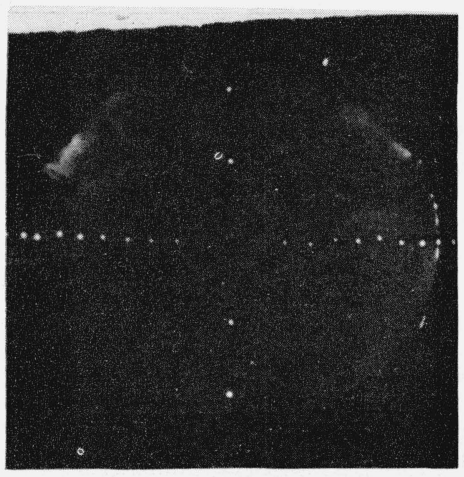

\section{DEC 4, 1958}
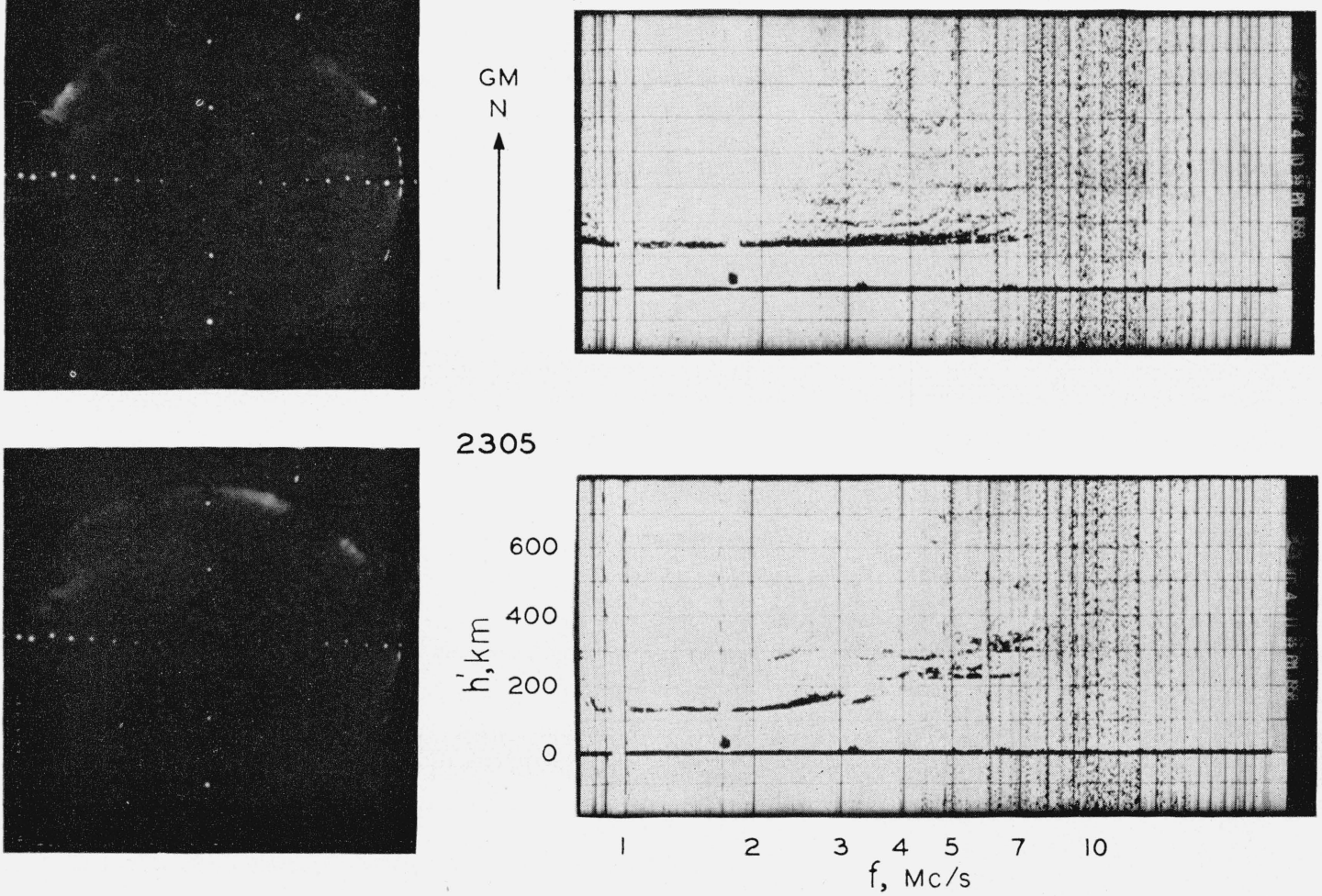

Figure 5. Simultaneous $C-3$ vertical ionosonde and all-sky camera record. 


\begin{tabular}{|c|c|c|c|}
\hline Time-date $\left(150^{\circ} \mathrm{WMT}\right)$ & Auroral activity & Ionospheric events & Remarks \\
\hline Figure $6 \quad 5$ Dec. 1958 & $\begin{array}{l}\text { Faint-to-medium diffuse homo- } \\
\text { geneous arc at } 65^{\circ} \text { south. } \\
\text { Very faint aurora near north- } \\
\text { ern horizon. } \\
\text { One or two faint homogeneous } \\
\text { arcs } 60^{\circ} \text { to } 80^{\circ} \text { south. Faint } \\
\text { aurora near northern horizon. } \\
\text { Bright homogeneous band at } \\
\text { zenith. Faint diffuse band at } \\
40^{\circ} \text { north. Faint-to-medium } \\
\text { diffuse homogeneous arc at } \\
70^{\circ} \text { south. Faint diffuse } \\
\text { aurora near northern horizon. }\end{array}$ & $\begin{array}{l}f E \mathrm{~s} \approx 3 \quad \mathrm{Mc} / \mathrm{s} \quad(E \mathrm{sr}) . \\
\text { spread-F present. } \\
f E \mathrm{~s} \approx 3 \mathrm{Mc} / \mathrm{s}(E \mathrm{sr}) . \\
\begin{array}{l}f E \mathrm{~s} \approx 8 \mathrm{Mc} / \mathrm{s}(E \mathrm{sf}) . \quad \text { Increased } \\
\text { spread- } F .\end{array}\end{array}$ & $\begin{array}{l}\text { The abrupt change in the re- } \\
\text { flecting property of the } E \text { - } \\
\text { layer as an auroral form } \\
\text { moves through the zenith is } \\
\text { well illustrated by this se- } \\
\text { quence. }\end{array}$ \\
\hline
\end{tabular}

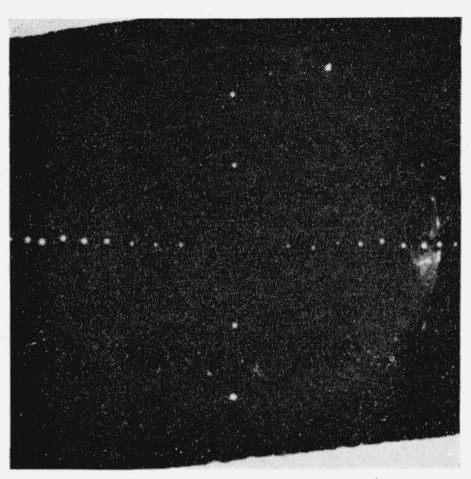

0005 DEC 5,1958

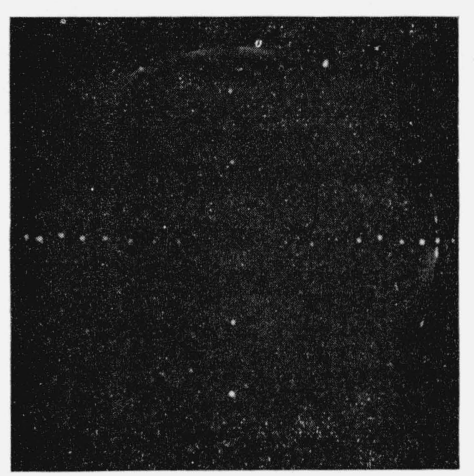

\section{0}
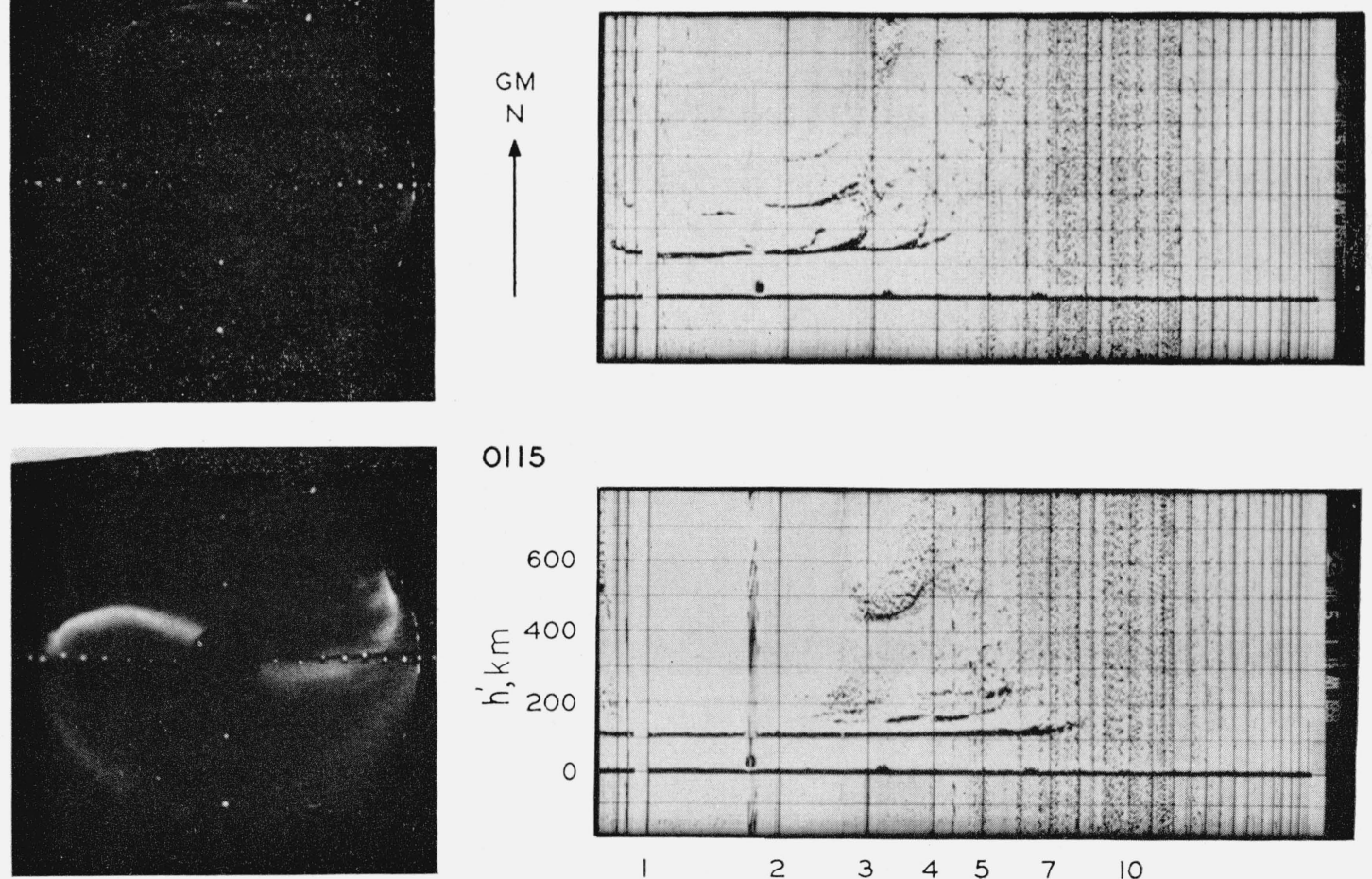

0115

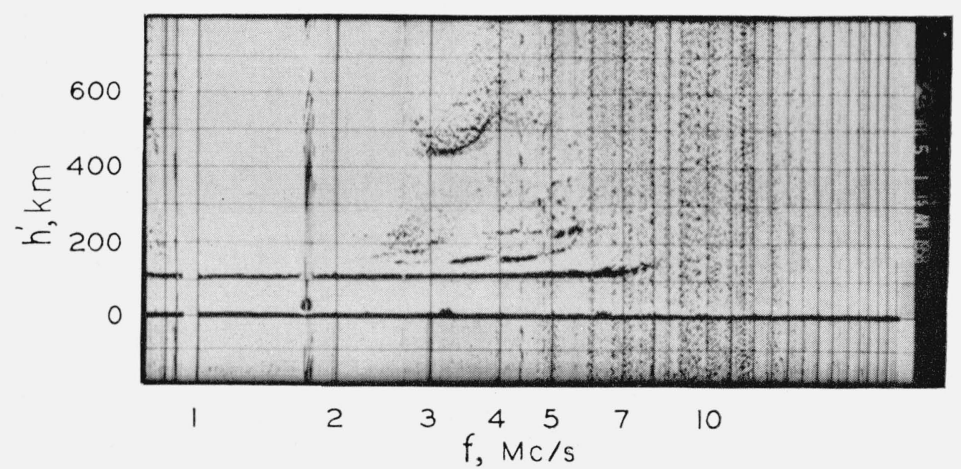

FiguRE 6. Simultaneous C-3 vertical ionosonde and all-sky camera record. 


\begin{tabular}{|c|c|c|}
\hline Time-date $\left(150 \mathrm{~W}^{\circ} \mathrm{MT}\right)$ & Auroral activity & Ionospheric events \\
\hline Figure $7 \underset{2345}{5 \text { Dec. } 1958}$ & No auroral activity $\ldots$ & $\begin{array}{l}\text { Extensive spread-F. }{ }^{f E \mathrm{~s} \approx} \\
3.4 \mathrm{Mc} / \mathrm{s} \text { Slant-Es }\left(E_{\mathrm{ss}}\right) \\
\text { echo. }\end{array}$ \\
\hline 2355 & $\begin{array}{l}\text { Very bright rayed band in zenith. } \\
\text { Brightest in west. }\end{array}$ & $\begin{array}{l}\text { Some spread- } F \text {. High degree } \\
\text { of stratification in } E \text {-region } \\
\text { and above. Esa echo with } \\
f E \mathrm{~s} \approx 8 \mathrm{Mc} / \mathrm{s} \text {. }\end{array}$ \\
\hline
\end{tabular}

Remarks

Another example of the abrupt changes which occur in reflecting properties of the $E$-layer when an auroral band crosses the magnetic zenith.

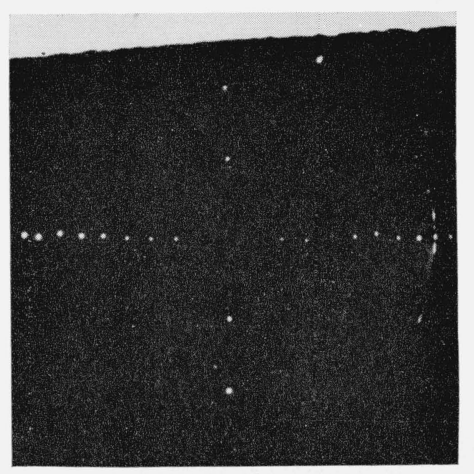

\section{DEC 5, 1958}
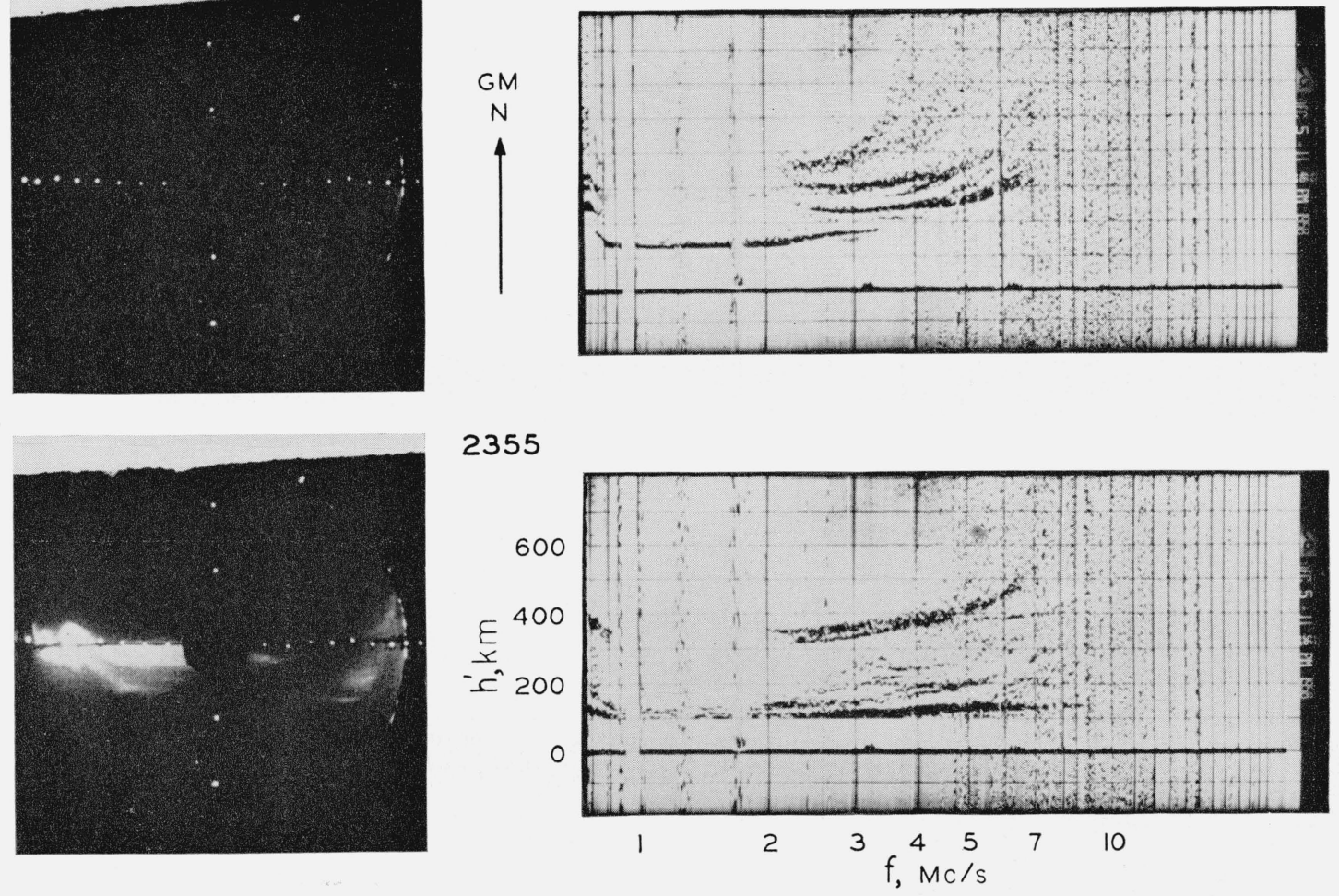

Figure 7. Simultaneous $C-3$ vertical ionosonde and all-sky camera record. 


\begin{tabular}{|c|c|c|c|}
\hline Time-date $\left(150^{\circ} \mathrm{WMT}\right)$ & Auroral activity & Ionospheric events & Remarks \\
\hline 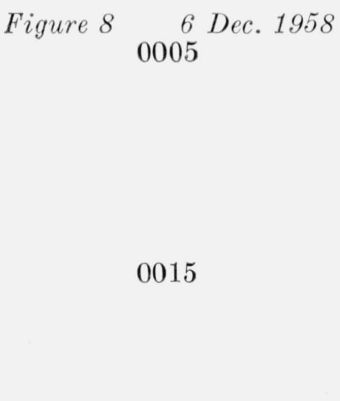 & $\begin{array}{l}\text { Bright rayed ares and bands } \\
\text { alined NW-SE. One arc ap- } \\
\text { proximately } 45^{\circ} \text { SW. Bright } \\
\text { bands and ares in NE. Pos- } \\
\text { sibly thin arc in zenith alined } \\
\text { nearly N-S, little aurora in } \\
\text { zenith compared to SW and } \\
\text { NE quadrants. } \\
\text { Probably medium-to-bright dif- } \\
\text { fuse pulsating aurora over } \\
\text { entire sky. }\end{array}$ & $\begin{array}{l}\text { Almost complete absorption } \\
\text { indicated. }\end{array}$ & $\begin{array}{l}\text { A careful examination of the } \\
\text { all-sky camera photos before } \\
\text { and after this observation } \\
\text { indicate a high probability } \\
\text { of pulsating aurora. }\end{array}$ \\
\hline
\end{tabular}

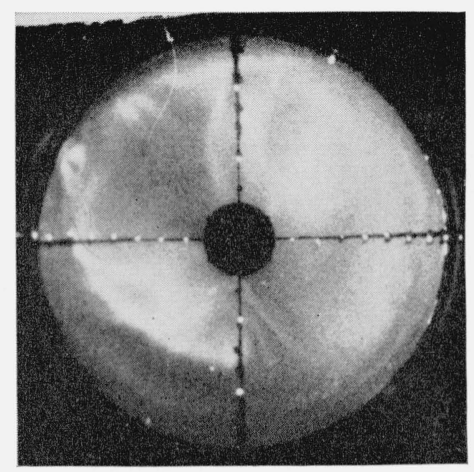

\section{DEC 6, 1958}
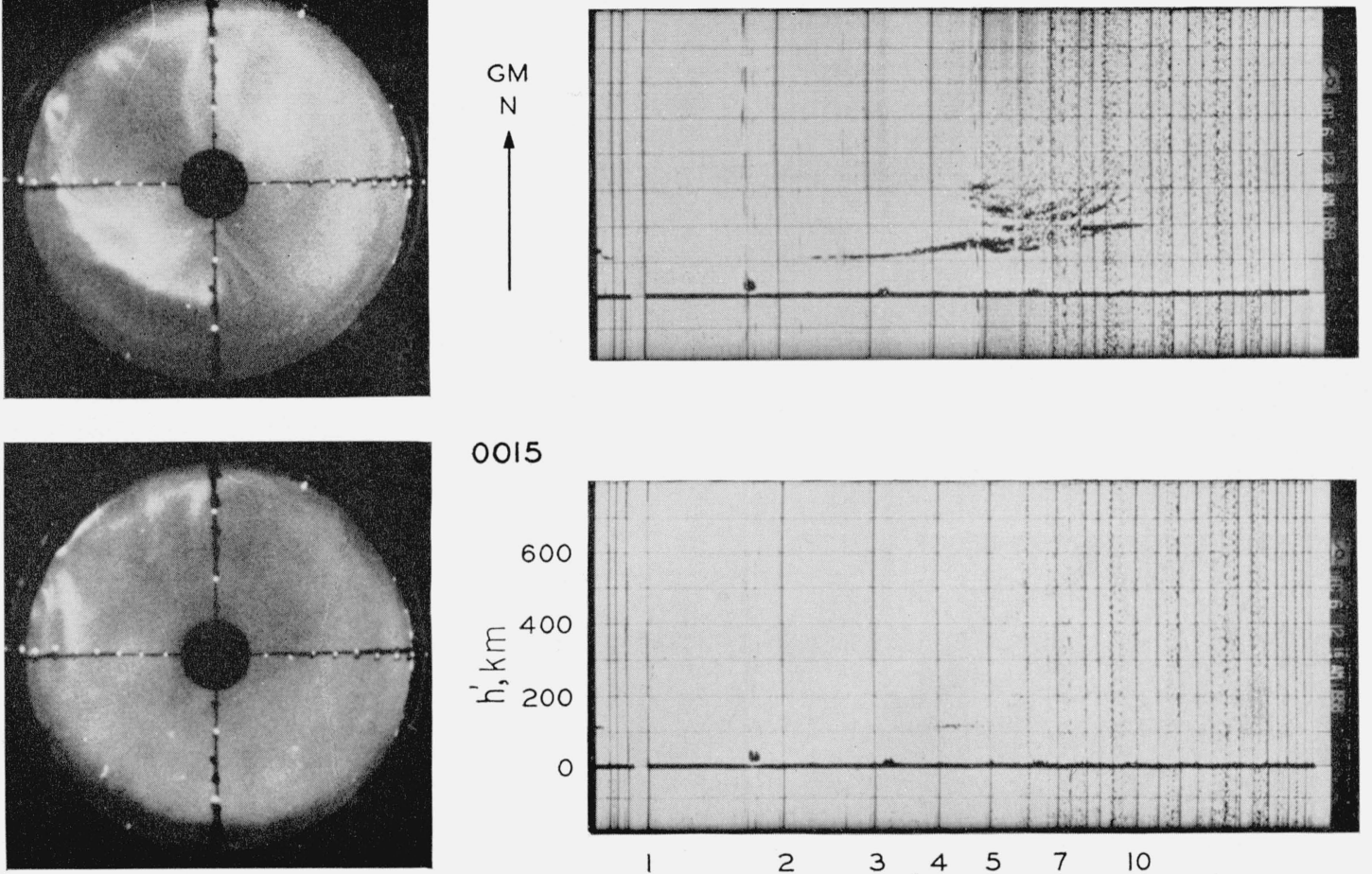

\section{5}

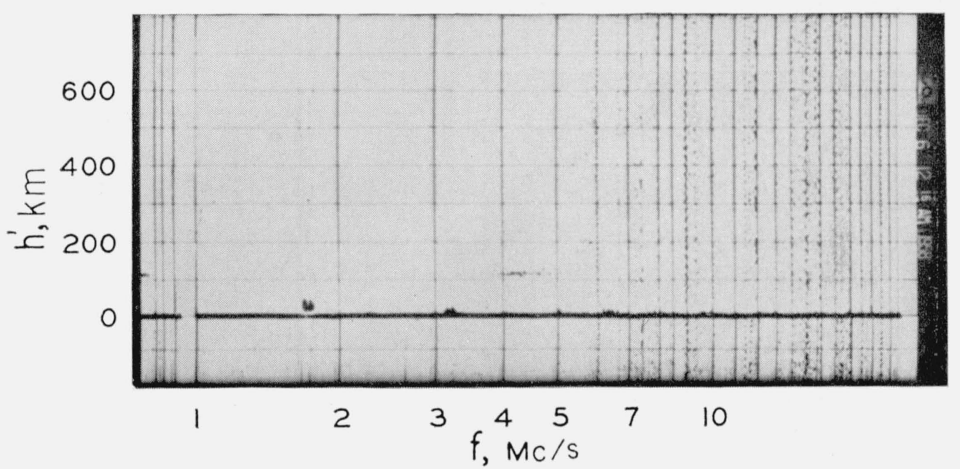

Figure 8. Simultaneous $C-3$ vertical ionosonde and all-sky camera record. 


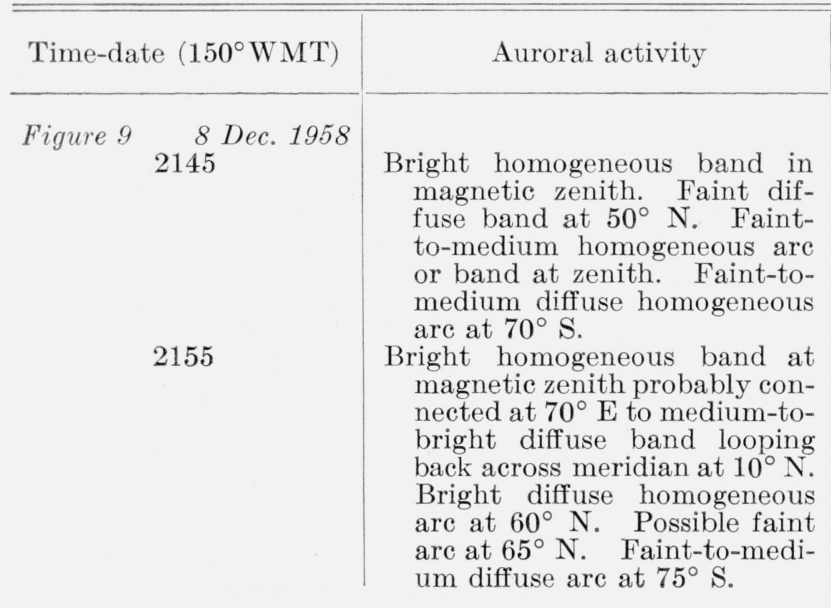

Ionospheric events

$E$ sf echo with $f E_{\mathrm{S}}>11 \mathrm{Mc} / \mathrm{s}$. High degree of stratification above $130 \mathrm{~km}$.

Reduced stratification. $E$ sf echo with $f E s \approx 10 \mathrm{Mc} / \mathrm{s}$.
Remarks

An example of the complicated structure of the ionosonde record during aurorally disturbed conditions.

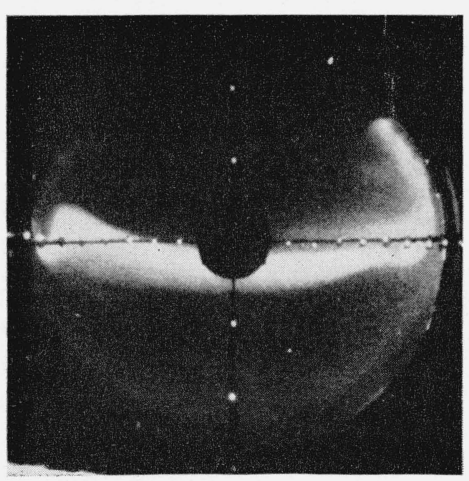

2145 DEC 8, 1958
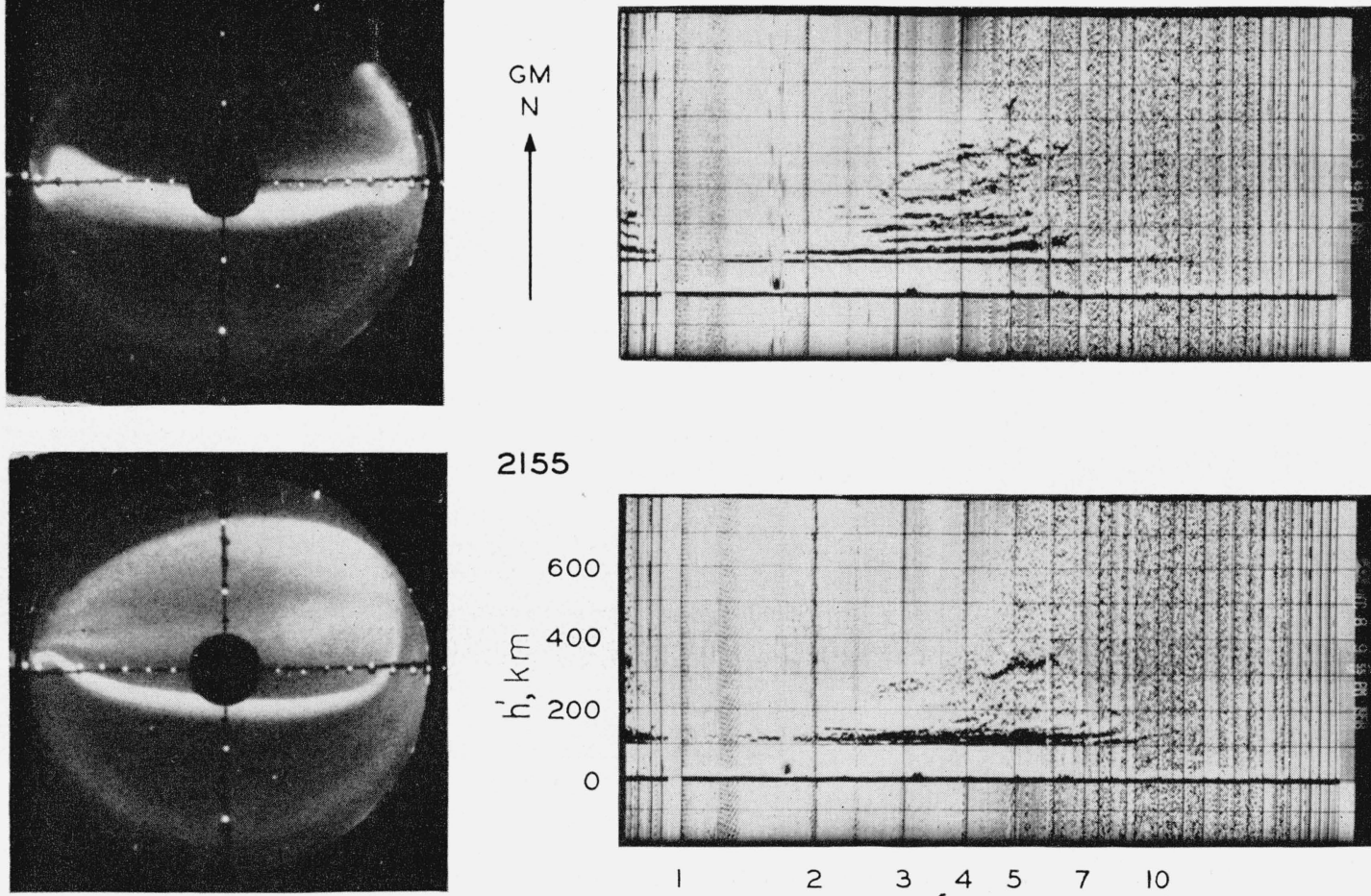

2155

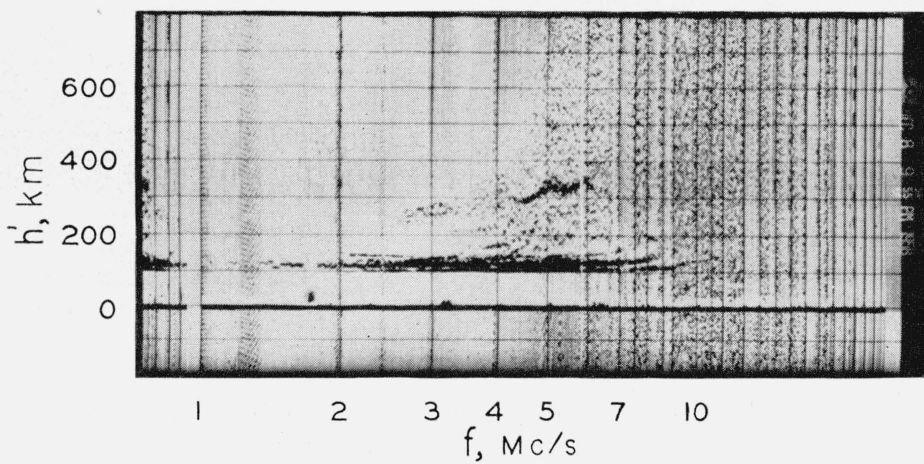

Figure 9. Simultaneous C-3 vertical ionosonde and all-sky camera record. 


\begin{tabular}{|c|c|c|}
\hline Time-date $\left(150^{\circ} \mathrm{W} \mathrm{MT}\right)$ & Auroral activity & Ionospheric events \\
\hline Figure $10 \begin{array}{c}9 \text { Dec. } 1958 \\
0130\end{array}$ & No auroral activity indicated...- & $\begin{array}{c}\text { Blanketing sporadic-E echo } \\
\text { with } f E \mathrm{~s}=5.5 \mathrm{Mc} / \mathrm{s} \text {. }\end{array}$ \\
\hline 0230 & No auroral activity indicated _..- & $\begin{array}{l}\text { Retardation type } E s \text { echo } \\
\text { (Esr) with } f E \mathrm{~s} \approx 5 \quad \mathrm{Mc} / \mathrm{s} \text {. } \\
\text { Partial transparency of } E \mathrm{~s} \\
\text { layer and multiple splitting } \\
\text { of } E \text {-trace. }\end{array}$ \\
\hline
\end{tabular}

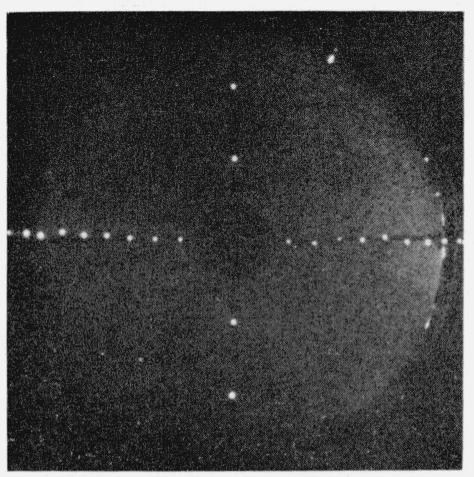

\section{DEC 9, 1958}
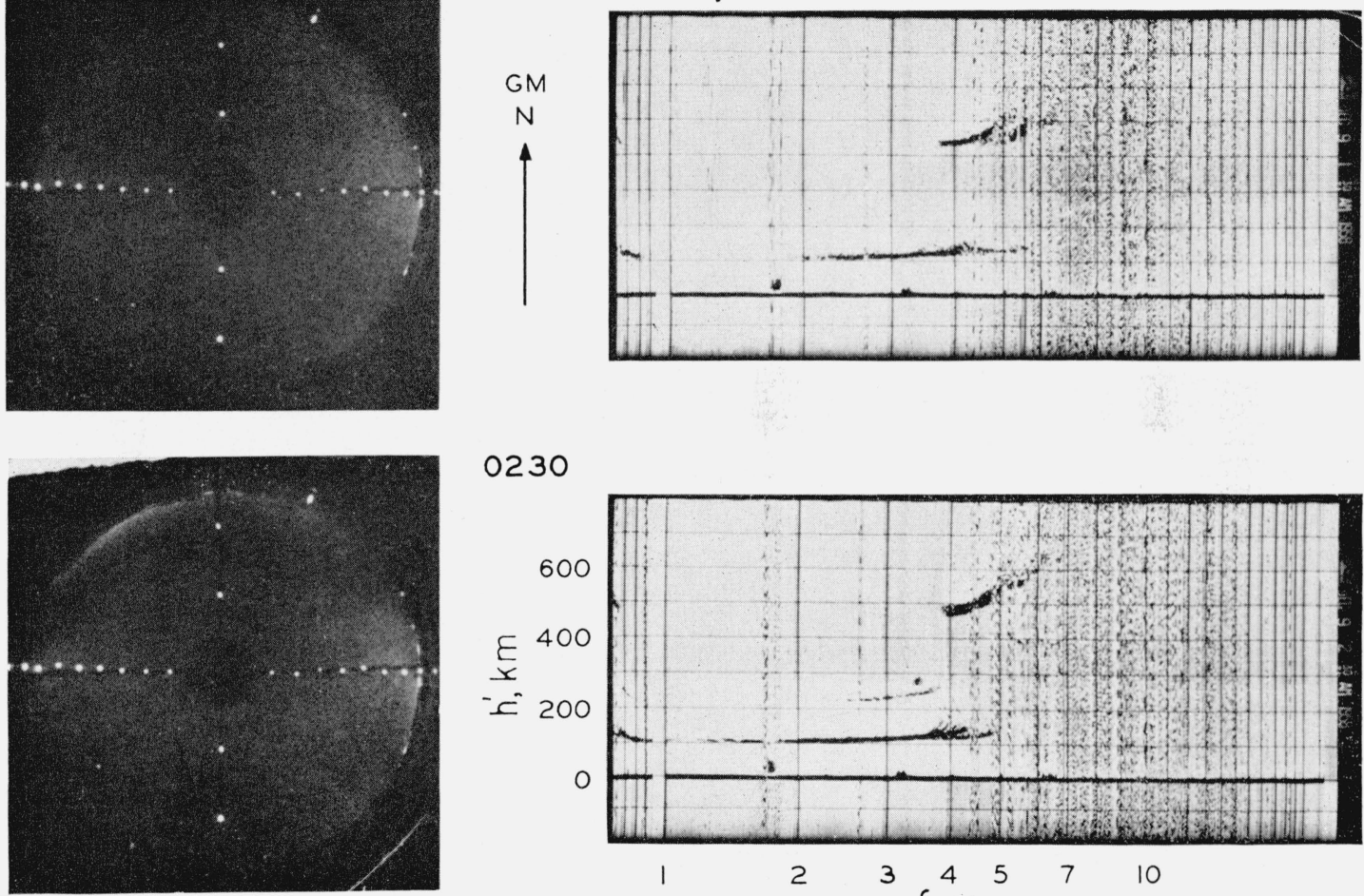

0230

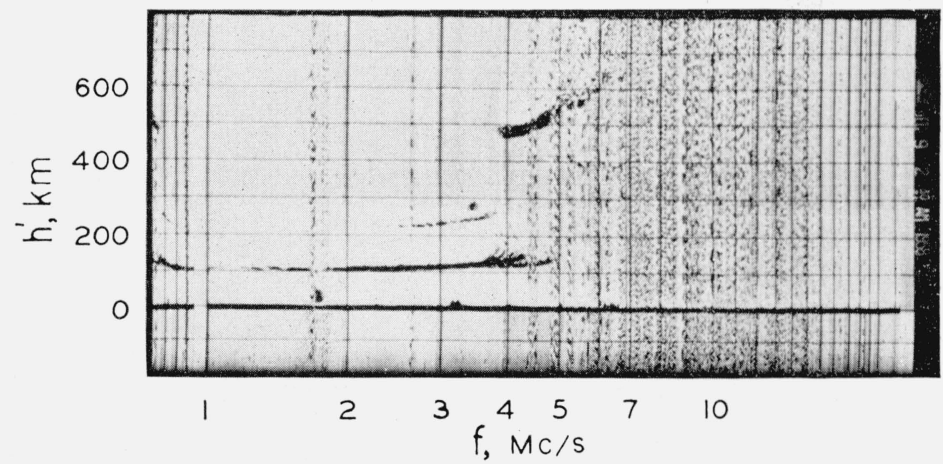

Figure 10. Simultaneous $C-3$ vertical ionosonde and all-sky camera record.

The following conclusions can be drawn from the simultaneous visual auroral and ionospheric sounding data presented in the atlas and the accompanying detailed descriptive material:

1. The motion of an auroral arc or band from a low elevation angle to a position near the zenith, is accompanied by an increase in the value of $f E s$.

2. This investigation indicates that

$$
\frac{f E_{\mathrm{s}} \text { (aurora at zenith) }}{f E_{\mathrm{s}}(\text { no zenith aurora) }}>2 \text {. }
$$

3. The highest value of $f E \mathrm{~s}$ is observed when an auroral arc or band is present at the astronomical zenith (not the magnetic zenith).

4. Zenithal aurora is generally accompanied by Esa or Esf traces.

5. Pulsating aurora is almost invariably accompanied by strong absorption or complete blackout.
This sequence is included to illustrate $E$ s layer conditions at high latitudes in the absence of zenithal auroral activity. 
The authors are indebted to Dr. T. N. Davis for discussions on the all-sky camera data, to Mrs. Sandra Fuller for cross-correlation computations, and to Mr. Dan Wilder for preparing the illustrations. The work reported here was sponsored by the Electronics Research Directorate, Air Force Office of Aerospace Research under Contract No. $19(604)-5574$.

\section{References}

Annals of the IGY, 3, Pt Section 6 (Pergamon Press, New York, N.Y., 1957).

Bates, H. F., The slant $E_{\text {s }}$ echo- a high frequency auroral echo, J. Geophys. Research 66, No. 2, 447-454 (1961).

Elvey, C. T., and Stoffregen, Auroral photography by an all-sky camera, Annals of the IGY V, Part II, 121-151 (Pergamon Press, New York, N.Y., 1957).

Heppner, J. P., E. C. Byrne, and A. E. Belon, The association of absorption and $E$ s ionization with aurora at high latitudes, J. Geophys. Research 5\%, 121-134 (1952).
Knecht, R. W., Relationship between aurora and sporadic- $E$ echoes at Barrow, Alaska, J. Geophys. Research 61, No. 1, 59-70 (1956).

Murcray, W. B., Some properties of the luminous aurora as measured by a photoelectric photcmeter, J. Geophys. Research 64, No. 8, 955-959 (Aug. 1959).

Owren, L., and R. D. Hunsucker, Arctic propagation studies at tropospheric and ionospheric modes of propagation, Final Report Contract No. AF 19(604)-1859, Geophysical Institute of the University of Alaska, College, Alaska (Oct. 1959).

Ratcliffe, J. A., Physies of the upper atmosphere, pp. 271-272 (Academic Press, New York, N.Y., 1960).

Thomas, J. A. and E. K. Smith, A survey of the present knowledge of sporadic- $E$ ionization, J. Atmospheric and Terrest. Phys. 13, Nos. 3/4, 295-314 (Feb. 1959).

Tryon, Helen M., Auroral index for College, Alaska derived from all-sky camera photographs, Sept. 1957-Dec. 1958. Scientific Report No.2, NSF Grant No. Y/22.6/327 Geophysical Institute of the University of Alaska (1959).

(Paper 66D5-218) 